\title{
Evaluation Of The Patient's Itching During Treating Hypertrophic Facial Scars By Hyaluronic Acid Injection With Automated Micro-Needling
}

\author{
Research Article
}

Ziad Alkadi', Muner Harfush², Muaaz Alkhouli ${ }^{3 *}$

${ }^{1}$ MSc in Oral and Maxillofacial Surgery, Faculty of Dentistry, Damascus University.

${ }^{2}$ Professor in Oral and Maxillofacial Surgery, Faculty of Dentistry, Damascus University.

${ }^{3}$ MSc in Pediatric Dentistry, Faculty of Dentistry, Damascus University.

\section{Abstract}

Background: The formation of facial scars is considered a next stage of wound healing process, which occurs when the facial tissues are exposed to damage or surgery. These scars are sometimes pathological scars that result from an abnormal response. While some scars may be socially acceptable, even admirable, scars of the face can be viewed as disfiguring or ugly. Facial scars can cause significant emotional distress due to their obvious location. Hypertrophic facial scars are characterized by an overgrowth of the collagen fibers within the scar and manifest in the form of tough nodal growths. Many treatment methods have been used in order to manage these scars to become as close as possible to the healthy skin nearby, but their applications was not without some unwanted side effects.

Objectives: This research studied the changes in itching during treating hypertrophic facial scars by hyaluronic acid injection with automated micro-needling according to Patient Scar Assessment Scale (PSAS).

Material and Methods: This research was a clinical trial. 12 Patients need treatment of hypertrophic facial scars were enrolled. 12 scars were treated with hyaluronic acid injection with automated micro-needling. Four treatment sessions were done with an interval of 30 days between each session and the next session. Four assessments of itching by patients were taken during treatment according to Patient Scar Assessment Scale (PSAS). Results: there are no statistically significant differences in the average assessment of the patient's itching among the four studied sessions $(\mathrm{P}>0.05)$.

Conclusion: Within the limitations of this research, we demonstrated that the use of hyaluronic acid injection with automated micro-needling in treating of hypertrophic facial scars is considered a safe technique with respect to the patient's itching scale.

Keywords: Dye Penetration; Glass Ionomer Cement; Microleakage.

\section{Introduction}

Scars are a common phenomenon as they develop after a skin injury in patients of all ages [1] and the defective development of these scars has not been understood in depth [2].

Hypertrophic scars on the face are formed following facial wounds and various facial surgeries. The causative factors may be excessive pulling force on the wound, bacteriosis, foreign reaction and inherited predisposition [3].

Hypertrophic facial scars are characterized by an overgrowth of the collagen fibers within the scar and manifest in the form of tough nodal growths that do not expand and do not extend beyond the edges of the original wound [4].
Although these scars do not pose a health risk, they can be very annoying to patients, as they are painful, raised, rigid and aesthetically unacceptable, which may negatively affect the patient,s quality of life [1]. Therefore, these scars were considered one of the most important challenges facing the surgeon, which requires careful treatment later in the event that they occur [5].

Many treatment methods have been used with the aim of managing these hypertrophic scars to become as close as possible to the healthy skin nearby, such as treatment with corticosteroids [6], cryotherapy [7], radiotherapy [8,9] and laser treatment [10], but all of these methods were not without some unwanted side effects.

Corticosteroids have been adopted with great frequency in treat-

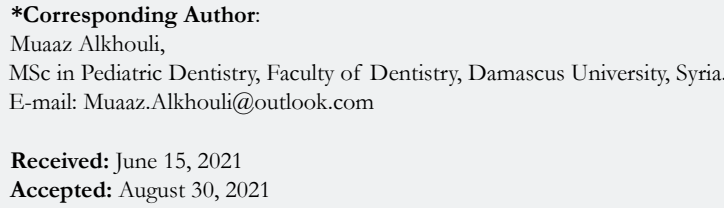

Copyright: Muaaz Alkhouli ${ }^{\circ} 2021$. This is an open-access article distributed under the terms of the Creative Commons Attribution License, which permits unrestricted use, distribution and reproduction in any medium, provided the original author and source are credited. 
ing hypertrophic scars by injecting triamcinolone into the scar tissue [6], but their use was accompanied by the emergence of some side effects such as atrophy, capillary expansion, and itching in the injection area [11], which reduced its use and required searching for alternative treatment methods.

Automated micro-needling has recently spread as a safe and effective dermatological treatment, as the basis for this treatment is the rupture of microscopic needles of old skin collagen structures by forming thousands of microscopic holes [12]. Where studies indicate that after pricking the skin, a group of enzymes are released; forming what is known as the metalloproteinase matrix and is responsible for breaking down most of the extracellular matrix proteins during normal tissue growth and transformation [13].

The automated micro-needling technique is accompanied by subsequent healing stages that begin with inflammation, which manifests as visible redness for about 48 hours, and the edema is considered uncommon [13]. Then the reproduction phase begins immediately with the introduction of new fibers from the third type collagen into the skin matrix, and the effect on the epidermal stem cells and dermis is still unknown [13]. Then comes the remodeling phase by transforming the formed collagen fibers into a more flexible type 1 collagen [14].

The discovery of automated micro-needling technique was only a coincidence when it recorded an unexpected improvement in the texture and color of hypopigmented facial scars and their general appearance after subjecting them to the camouflaging tattoo based on needles [15], as these needles work within specific depths and are subject to adjustment, and these depths range from $0.25 \mathrm{~mm}$ to $2.5 \mathrm{~mm}[16]$.

The dermaroller device, or the so-called skin wheel, was first used in automatic micro-needling, which is a grip equipped with a cylindrical wheel bearing on its surface 192 needles of stainless steel with a diameter $0.25 \mathrm{~mm}$ and a length of $1.5 \mathrm{~mm}$ [14]. Then the dermapen device, or the so-called skin pen, appeared, as the mechanisms of action of the two devices is similar in terms of relying on microscopic skin needling to stimulate the healing process more regularly and within microscopic areas, which is positively reflected in improving the appearance of the skin, reshaping it and increasing its elasticity [17], but the advantage of the dermapen over the dermaroller is highlighted by reducing the extent of damage to the skin [18], and thus Dermapen has received approval from the US Food and Drug Administration and the award for the best professional device in skin rejuvenation, as it is used in the treatment of common acne scars, burn scars, tension lines, wrinkles and hair loss [12, 17].

Most of the advantages regarding skin treatment with Automated micro-needling with the dermapen are based on the absence of an open wound in patients and there is no risk of photosensitivity in addition to the fact that the device is an inexpensive therapeutic alternative [19], while the disadvantage arises through the possibility of skin bruising in the treatment area during the first two days [12].

Hyaluronic acid is a glycosaminoglycans present in the epidermis with a high molecular weight and its molecules are found on the skin cell envelope and in the cellular space of skin and the vitreous of the eye and in the joints and muscles [20], and has a role in many important vital functions, such as regulating cellular adhesion and cellular movement, managing differentiation, and conferring mechanical and biological properties of tissues [21].

The first thing that hyaluronic acid was isolated from the vitreous in the eyes of cows was later called Hyalus, and it is present in all living species and does not require an allergy test before injection [22].

There are two types of hyaluronic acid, either it is animal, which is extracted from rooster combs and has a high molecular weight and a low concentration, or it is non-animal as it is extracted by the bacterial fermentation process of streptococcus and has a low molecular weight and a high concentration [23].

Hyaluronic acid has been used extensively during the past two decades in eye surgery, wound repair and arthritis treatment, due to its water-soluble properties and its lubricant or sticky properties [24]. With the advancement of biotechnology, this substance has been developed into multiple forms and different molecular sizes with the aim of using it for cosmetic purposes [23], which prompted us to adopt it in this research in conjunction with automated micro-needling in order to treat hypertrophic facial scars.

\section{Materials and Methods}

This research was a clinical study. And it was done from September 2018 to February 2020 at the clinic of Department of Oral and Maxillofacial Surgery, Faculty of Dentistry, University of Damascus, Damascus, Syria.

12 patients ( 5 males have 5 scars, 7 females have 7 scars) requiring treating their scars were included in this research (Table 1). These facial hypertrophic scars located in the maxillofacial region resulting from oral and maxillofacial surgery operations. The mean patient age was 29 years (Table 2). The patients were given written information about the research, and their informed approval was obtained.

\section{Inclusion Criteria}

- $\quad$ Ages of Patients from 18 to 45 years old.

- Patients have had maxillofacial surgeries more than six months ago from the date of the operation and they complain about the presence of supsequent facial hypertrophic scars.

- $\quad$ Patients with type III or IV Fitzpatrick classification [25], the most common type in the Middle East.

- The patient must be cooperative, mentally capable, and committed to the boycott.

\section{As Inclusion Criteria for the scar [26], they were}

- The scar is not associated with a local or systemic infection, gangrene, or nonvascular tissue.

- The scar should be at least 6 months old.

- In this research, the length of the scar ranged between $1-3 \mathrm{~cm}$, its height was $2 \mathrm{~mm}$, and its width ranged between $2-3 \mathrm{~mm}$.

\section{Exclusion Criteria}

- Oncology patients who are subjected to radiotherapy in the 
Table 1. Gender information of the enrolled patients.

\begin{tabular}{|c|c|c|c|}
\hline \multirow{2}{*}{ Parameters } & \multicolumn{2}{|c|}{ Gender } & \multirow{2}{*}{ Total } \\
\cline { 2 - 3 } & Male & Female & \\
\hline Frequency & 5 & 7 & 12 \\
\hline Percentage & $41.70 \%$ & $58.3 \%$ & $100.00 \%$ \\
\hline
\end{tabular}

Table 2. Age information of the enrolled patients.

\begin{tabular}{|c|c|c|c|}
\hline Parameters & Number & Mean & Standard deviation \\
\hline Age $(\mathrm{yr})$ & 12 & 29 & 5.74 \\
\hline
\end{tabular}

face area.

- The presence of diseases that affect the healing process, such as diabetes or immune diseases.

- The presence of bleeding disorders.

- The presence of skin diseases such as psoriasis, vitiligo and skin infections.

- Patients who have had their scars treated with botulinum toxin or fillers in a previous period between six and eight months.

- Lactation or pregnancy.

\section{Materials and tools used in the research}

- Clinical examination tools: (gloves- masks- sterile gauze).

- Photography tools: digital camera.

- Sterilization tools: Hexamidine surface disinfectant, concentration $0.1 \mathrm{ml}$.

- Surface anesthetic: Cosmocaine Plus.

- Automated micro-needling device and its heads. the Dermapen device was used, which is an advanced technology for vertical pricking of the skin through several needles that puncture the skin with an automatic vibratory function. The movement of the needles up and down vertically and the depth of entry of the needles is controlled from $0.25 \mathrm{~mm}$ to $2.5 \mathrm{~mm}$ and at seven speed levels ranging from 1 to 7 pricks per second, and the depth of entry is adjusted according to the target area by special keys. The device has been calibrated in our study to be a prick depth of $2 \mathrm{~mm}$ and at speed levels of 5 pricks per second, according to the instructions of the device manufacturer [27].

- Hyaluronic acid. CytoCare was used from the French company Revitacare, which is a mixture of $32 \mathrm{mg} / \mathrm{ml}$ non-crosslinked biotechnological hyaluronic acid and CT50 rejuvenating complex [28]. It was filled with insulin syringes and injected into the thread-treated scars.

\section{Surgical Procedure}

After scar was clinically examined by direct vision and ensured that it complied with the conditions, an optical image was made of the location of the target scar (Figure1). The treatment was divided into 4 sessions with an interval of 30 days between each session and the next session $[29,30]$, where the work was done in each session as follows: The surface of the scar was cleaned well with $0.01 \mathrm{ml}$ hexamidine solution, then the surface anesthetic was put for 45 minutes [31], and then removed it with sterile gauze. hyaluronic acid was applied by injecting it into the treated scar streakly over the entire length of the scar surface (Figure 2). A micro-needling was performed on the treated scar after preparing the first with a new needle head and determining the appropriate speed and depth of puncture. The dermapen was lubricated on the skin at an angle of 90 degrees without applying any pressure, according to the three directions of vertical, horizontal and inclined, and the movement was steadily and in one direction (Figure 3,4$)$, the area was wipped with a sterile gauze. The duration of work in each session was between 5-10 minutes [27]. Patients were asked Post-each session not to be exposed to the sun for 24 hours after the treatment session, and were allowed to return to their work one day after the treatment session.

\section{Study Method}

The Patient Scar Assessment Scale (PSAS) consists of 6 numerically recorded items that give at the end a total scale number, and the total gives the overall score for the scale [32]. The scale of patient includes 6 questions about pain, itching, color, hardness, thickness, and general appearance, and each of the six items has a scale of 10 degrees, where the score of 10 corresponds to the wrost scar that can be imagined or felt, while the score of 1 reflects the state of normal skin (Figure 5). In this research, patients were asked to give an overall assessment of their itching using this scale for all treatment sessions (Figure 6).

\section{Statistical Analysis}

The sample size was calculated according to (G Power 3.1.7) program, considering that the $\mathrm{t}$ - test used is: $\mathrm{t}$ - test for cross linked or dependent samples and significance level: $5 \%$, study strength: $80 \%$, and effect size: 1.39 after 4 months with maximum standard deviations: 7.68 , and then entered the information to the program was processed, so the required sample size was 12 cases. Statistical analysis of the variables of this research (itching scale) was done using a program Statistical Package for the Social Sciences (SPSS) version 20. The t-test was used to evaluate itching changes. A dependent t-test was performed to study the significance of the differences in the changes of itching scale. (The P-value $\leq 0.05$ was considered statistically significant).

\section{Results}

This research evaluated the changes in itching scale (Table 3). The research showed that there are no statistically significant differences in the average assessment of the patient's itching among the four studied sessions $(\mathrm{P}>0.05)$ (Table 4). 
Figure 1. An image showing the scar before the treatment session.

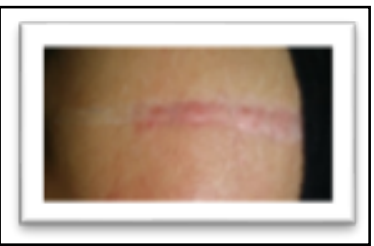

Figure 2. An image showing the scar during the injection of hyaluronic acid.

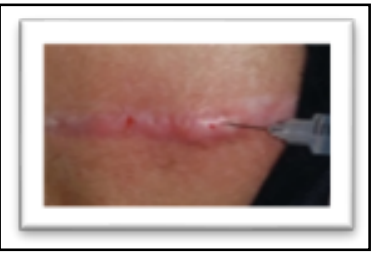

Figure 3. An image showing the scar during automated micro-needling.

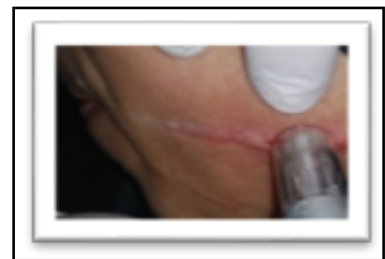

Figure 4. An image showing the scar after automated micro-needling directly.

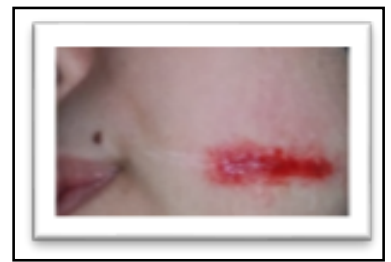

Figure 5. Patient's Scar Assessment Scale (PSAS) An image showing Figure 5.

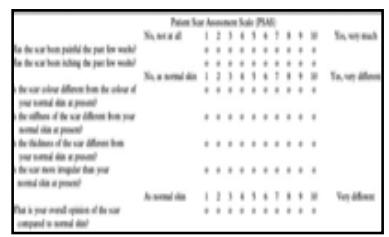

Figure 6. An image showing the treated scar after 4 months of treatment.

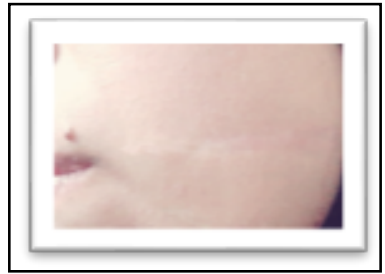

$\mathrm{B}-\mathrm{A}$ : In the second session - in the first session.

C-A: In the third session - in the first session.

D-A: In the fourth session - in the first session.

C-B: In the third session - in the second session.

D-B: In the fourth session - in the second session.

D-C: In the fourth session - in the third session.

\section{Discussion}

A scar is an unavoidable end result of wound healing; Scarring is a natural process of healing after damage to the skin that extends to the reticular dermis. While some scars may be socially acceptable, even admirable, scars of the face can be viewed as disfiguring or ugly [33]. Facial scars can cause significant emotional distress due to their obvious location $[34,35]$. Hypertrophic scars are charac- terized by an overgrowth of the collagen fibers within the scar and manifest in the form of tough nodal growths [4]. Many treatments have been used in the management of hypertrophic facial scars, but their application was not without some unwanted side effects. Steroid injection may cause skin depression, atrophy and itching $[11,36,37]$. Potential complications of radiation therapy are divided into erythema or itching $[38,39]$. LASERS are associated with prolonged erythema, hence the next itch [40, 41]. Many scar creams are available, Some creams that contain vitamin E, its use was accompanied by the appearance of following allergic reactions [42]. Hyaluronic acid was used In this research in combination with automated micro-needling for treating these scars, in contrast to studies that used micro-needling alone as a skin treatment without applying any materials [13, 19]. The treatment was performed in four sessions and the interval between sessions was 30 days based on previous studies in this regard [29, 
Table 3. Descriptive statistics of the changes in the itching during the four studied sessions.

\begin{tabular}{|c|c|c|c|c|c|c|}
\hline \multirow{3}{*}{ Parameters } & Studied session & \multirow{2}{*}{ Num } & \multirow{2}{*}{ Mean } & \multirow{2}{*}{$\begin{array}{c}\text { Standard devia- } \\
\text { tion }\end{array}$} & \multicolumn{2}{|c|}{ Confidence Interval 95 \% } \\
\cline { 5 - 7 } & & & & Lower limit & Upper limit \\
\hline \multirow{3}{*}{ Itching } & 1 & 12 & 2.29 & 0.74 & 1 & 6 \\
\cline { 2 - 7 } & 2 & 12 & 2.34 & 0.68 & 1 & 5 \\
\cline { 2 - 7 } & 3 & 12 & 2.33 & 0.68 & 1 & 5 \\
\hline
\end{tabular}

Table 4. $T$ test for dependent samples to study the changes in the itching during the four studied sessions.

\begin{tabular}{|c|c|c|c|c|c|}
\hline Parameters & $\mathbf{T}$ & P- value & Mean Difference & $\begin{array}{c}\text { Comparison of scar assessment } \\
\text { values between the two sessions }\end{array}$ & $\begin{array}{c}\text { Confidence Interval 95 \% de- } \\
\text { grees of freedom }\end{array}$ \\
\hline \multirow{5}{*}{ Itching } & 0.405 & 1.185 & 0.09 & B-A & 11 \\
\cline { 2 - 6 } & 0.405 & 1.185 & 0.09 & C-A & 11 \\
\cline { 2 - 6 } & -0.376 & 1.205 & -0.08 & D-A & 11 \\
\cline { 2 - 6 } & 0 & 1 & 0 & C-B & 11 \\
\cline { 2 - 6 } & -1.363 & 0.451 & -0.17 & D-B & 11 \\
\hline
\end{tabular}

30]. From this interval between sessions given sufficient time to effect a change in the properties of the treated scar. The patient's Scar Assessment Scale (PSAS) was also used, and this same scale was adopted in similar studies [32], In contrast to the use of the electronic Viso-scan, which gives values on skin color and scar depth [43], but is completely unable to give values about the other variables of scar such as itching, for example, was the variable studied in this research.

According to this research, the changes in itching scale were found to be not statistically significant $(\mathrm{P}>0.05)$. These results agree with Aust et al., 2011 [12]; Jeong et al., 2017 [18]; Majid et al., 2014 [19] who Indicated the safety of using the automated micro-needling technique in different skin treatments and treating facial scars.

\section{Conclusion}

Within this research, we find that the use of hyaluronic acid injection with automated micro-needling in treating of hypertrophic facial scars is considered a safe technique with respect to the patient's itching scale.

\section{References}

[1]. van Drooge AM, Vrijman C, van der Veen W, Wolkerstorfer A. A randomized controlled pilot study on ablative fractional $\mathrm{CO} 2$ laser for consecutive patients presenting with various scar types. Dermatol Surg. 2015 Mar;41(3):371-7.Pubmed PMID: 25705952.

[2]. Del Toro D, Dedhia R, Tollefson TT. Advances in scar management: prevention and management of hypertrophic scars and keloids. Curr Opin Otolaryngol Head Neck Surg. 2016 Aug;24(4):322-9.Pubmed PMID: 27163611.

[3]. Winter GD. Some factors affecting skin and wound healing. J Tissue Viability. 2006 May 1;16(2):20-3.

[4]. Berman B, Maderal A, Raphael B. Keloids and hypertrophic scars: pathophysiology, classification, and treatment. Dermatol Surg. 2017 Jan 1;43:S318.

[5]. Phillips TJ, Gerstein AD, Lordan V. A randomized controlled trial of hydrocolloid dressing in the treatment of hypertrophic scars and keloids. Dermatol Surg. 1996 Sep;22(9):775-8.Pubmed PMID: 8874525.

[6]. KETCHUM LD, SMITH J, ROBINSON DW, MASTERS FW. The treatment of hypertrophic scar, keloid and scar contracture by triamcinolone ace- tonide. Plast Reconstr Surg. 1966 Sep 1;38(3):209-18.

[7]. Barara M, Mendiratta V, Chander R. Cryotherapy in treatment of keloids: evaluation of factors affecting treatment outcome. J Cutan Aesthet Surg. 2012 Jul; $5(3): 185-9$

[8]. Kovalic JJ, Perez CA. Radiation therapy following keloidectomy: a 20-year experience jeffrey. Int J Radiat Oncol Biol Phys. 1989 Jul 1;17(1):77-80.

[9]. Ogawa R, Mitsuhashi K, Hyakusoku H, Miyashita T. Postoperative electronbeam irradiation therapy for keloids and hypertrophic scars: retrospective study of 147 cases followed for more than 18 months. Plast Reconstr Surg. 2003 Feb 1;111(2):547-55.

[10]. Sobhy N, El-Shafaei A, Kamal N. STUDY OF FRACTIONAL ABLATIVE LASER IN SURGICAL AND POST TRAUMATIC SCAR. Our Dermatol Online. 2012 Jul 1;3(3): 95-188.

[11]. Atiyeh BS. Nonsurgical management of hypertrophic scars: evidence-based therapies, standard practices, and emerging methods. Aesthetic Plast Surg. 2007 Oct 1;31(5):468-92.

[12]. Aust MC, Fernandes D, Kolokythas P, Kaplan HM, Vogt PM. Percutaneous collagen induction therapy: an alternative treatment for scars, wrinkles, and skin laxity. Plast Reconstr Surg. 2008 Apr;121(4):1421-1429.Pubmed PMID: 18349665

[13]. Liebl H, Kloth LC. Skin cell proliferation stimulated by microneedles. J Am Coll Clin Wound Spec. 2012 Mar 1;4(1):2-6.

[14]. Schwarz M, Laaff H. A prospective controlled assessment of microneedling with the Dermaroller device. Plast Reconstr Surg. 2011 Jun 1;127(6):146e$8 \mathrm{e}$.

[15]. Camirand A, Doucet J. Needle dermabrasion. Aesthetic Plast Surg. 1997 Jan-Feb;21(1):48-51. PubmedPMID: 9204168.

[16]. El-Fakahany H, Medhat W, Abdallah F, Abdel-Raouf H, Abdelhakeem M. Fractional Microneedling: A Novel Method for Enhancement of Topical Anesthesia Before Skin Aesthetic Procedures. Dermatol Surg. 2016 Jan;42(1):50-5.Pubmed PMID: 26671202.

[17]. Wilson, K.A. Powderful and economical Dermapen, Expends the Boundaries of Microneedle Dermabrasion. Aesthetic Guide.2012; 15 (6): 3-11.

[18]. Jeong HR, Lee HS, Choi IJ, Park JH. Considerations in the use of microneedles: pain, convenience, anxiety and safety. J Drug Target. 2017 Jan;25(1):29-40.Pubmed PMID: 27282644.

[19]. Majid I, Sheikh G, September PI. Microneedling and its applications in dermatology. Prime Int J Aesthetic Anti- Ageing Med. 2014 Sep 15;4(7):44-49.

[20]. Necas JB, Bartosikova L, Brauner P, Kolar JJ. Hyaluronic acid (hyaluronan): a review. Vet Med. 2008 Aug 1;53(8):397-411.

[21]. Shu XZ, Liu Y, Palumbo FS, Luo Y, Prestwich GD. In situ crosslinkable hyaluronan hydrogels for tissue engineering. Biomaterials. 2004 Mar 1;25(78):1339-48

[22]. Cai S, Xie Y, Bagby TR, Cohen MS, Forrest ML. Intralymphatic chemotherapy using a hyaluronan-cisplatin conjugate. J. Surg. Res. 2008 Jun $15 ; 147(2): 247-52$

[23]. Sánchez-Carpintero I, Candelas D, Ruiz-Rodríguez R. Materiales de relleno: tipos, indicaciones y complicaciones [Dermal fillers: types, indications, and complications]. Actas Dermosifiliogr. 2010 Jun;101(5):381-93. Spanish. 


\section{Pubmed PMID: 20525480}

[24]. Simoni RD, Hill RL, Vaughan M, Hascall V. The discovery of hyaluronan by Karl Meyer. J. Biol. Chem. 2002 Sep 27;277(39):e27-72.

[25]. Cole PD, Hatef DA, Kaufman Y, Pozner JN. Laser therapy in ethnic populations. Semin Plast Surg. 2009 Aug;23(3):173-177.

[26]. van Drooge AM, Vrijman C, van der Veen W, Wolkerstorfer A. A randomized controlled pilot study on ablative fractional CO2 laser for consecutive patients presenting with various scar types. Dermatol Surg. 2015 Mar;41(3):371-7.Pubmed PMID: 25705952.

[27]. Dermapen . Dermapen informations.2014.

[28]. Revitacare . Cytocare.2014; 532 .

[29]. Rabello FB, Souza CD, Farina JA. Update on hypertrophic scar treatment. Clinics. 2014;69(8):565-73.

[30]. Arora S, Gupta PB. Automated microneedling device-a new tool in dermatologist's kit-a review. J. Pak. Assoc. Dermatol. 2012 Oct 1;22(4):22-30.

[31]. Chiang YZ, Al-Niaimi F, Madan V. Comparative Efficacy and Patient Preference of Topical Anaesthetics in Dermatological Laser Treatments and Skin Microneedling. J Cutan Aesthet Surg. 2015 Jul-Sep;8(3):143-6.Pubmed PMID: 26644737.

[32]. Van De Kar AL, Corion LU, Smeulders MJ, Draaijers LJ, van der Horst CM, Van Zuijlen PP. Reliable and feasible evaluation of linear scars by the Patient and Observer Scar Assessment Scale. Plast Reconstr Surg. 2005 Aug $1 ; 116(2): 514-22$

[33]. Vincent AG, Kadakia S, Barker J, Mourad M, Saman M, Ducic Y. Management of facial scars. Facial Plast Surg. 2019 Dec;35(06):666-71.

[34]. Heffelfinger RN, Sanan A, Bryant LM. Management of forehead scars. Facial Plast Surg Clin North Am. 2017;25(01):15-24.
[35]. Lighthall JG, Fedok FG. Treating Scars of the Chin and Perioral Region. Facial Plast Surg Clin North Am. 2017 Feb;25(1):55-71.Pubmed PMID: 27888894.

[36]. Thomas JR, Somenek M. Scar revision review. Arch Facial Plast Surg. 2012 May 1;14(3):162-74.

[37]. Capon A, Iarmarcovai G, Gonnelli D, Degardin N, Magalon G, Mordon S. Scar prevention using laser-assisted skin healing (LASH) in plastic surgery. Aesthetic Plast Surg. 2010 Aug 1;34(4):438-46.

[38]. Speranza G, Sultanem K, Muanza T. Descriptive study of patients receiving excision and radiotherapy for keloids. Int J Radiat Oncol Biol Phys. 2008 Aug 1;71(5):1465-9.

[39]. Ogawa, R., MITSUHASHI, K. and MIYASHITA, T. Postoperative electron-beam irradiation therapy for kiloids and hypertrophic scars. Plast ReconstrSurg.2003; 111: 53-547.

[40]. Hassouneh B, Newman JP. Lasers, fillers, and neurotoxins: avoiding complications in the cosmetic facial practice. Facial Plast Surg Clin North Am. 2013 Nov;21(4):585-98.Pubmed PMID: 24200377.

[41]. Mahmoud BH, Srivastava D, Janiga JJ, Yang JJ, Lim HW, Ozog DM. Safety and efficacy of erbium-doped yttrium aluminum garnet fractionated laser for treatment of acne scars in type IV to VI skin. Dermatol Surg. 2010 May;36(5):602-9.Pubmed PMID: 20384757.

[42]. Baumann LS, Md JS. The effects of topical vitamin E on the cosmetic appearance of scars. Dermatol Surg. 1999 Apr;25(4):311-5.

[43]. Khan BA, Akhtar N, Waseem K, Mahmood T, Rasul A, Iqbal M. Visio Scan VC98, Corneometer MPA 5 and Tewameter MPA 5. African J. Pharm. Pharmacol. 2012 Jan 22;6(3):225-7. 